\title{
Arrhythmia Graphics
}

\section{Two pacing spikes on the QRS complex in a single-chamber pacemaker}

\section{Dinesh Choudhary ${ }^{a, *}$, Shunmuga Sundaram ${ }^{b}$, Anees Thajudeen ${ }^{c}$, Narayanan Namboodiri ${ }^{d}$}

${ }^{a}$ Fellow in Cardiac Electrophysiology, Department of Cardiology, Sree Chitra Tirunal Institute for Medical Sciences and Technology (SCTIMST), Thiruvananthapuram 695011, Kerala, India

${ }^{\mathrm{b}}$ Senior Resident, Department of Cardiology, Sree Chitra Tirunal Institute for Medical Sciences and Technology (SCTIMST),

Thiruvananthapuram 695011, Kerala, India

${ }^{c}$ Assistant Professor, Department of Cardiology, Sree Chitra Tirunal Institute for Medical Sciences and Technology (SCTIMST),

Thiruvananthapuram 695011, Kerala, India

${ }^{\mathrm{d}}$ Associate Professor, Department of Cardiology, Sree Chitra Tirunal Institute for Medical Sciences and Technology (SCTIMST),

Thiruvananthapuram 695011, Kerala, India

\section{A R T I C L E I N F O}

\section{Article history:}

Received 28 May 2012

Received in revised form

23 July 2012

Accepted 24 August 2012

Available online $\mathrm{xxx}$

Keywords:

AutoCapture

Single-chamber pacemaker

Hysteresis

Evoked potential

Pseudofusion

\begin{abstract}
A B S T R A C T
AutoCapture algorithm helps the pacemakers to automatically adjust output close to the pacing threshold. This algorithm monitors the evoked response signal of myocardial depolarization, and delivers a high output back-up pulse if there is a loss of capture. This case, with two pacemaker spikes on the QRS complexes in a patient with VVI pacemaker, simulating a sensing failure, demands clear understanding of AutoCapture function before labeling the pacemaker malfunction.
\end{abstract}

Copyright (c) 2012, Cardiological Society of India. All rights reserved. 57-year-old male was implanted with a single-chamber pacemaker (VVI, Regency SC+, Model 2402L, St. Jude Medical, lower rate $50 \mathrm{bpm}$, hysteresis off) for symptomatic sick sinus syndrome in 1998. On routine follow-up, he was noted to have the ECG recorded in Fig. 1A. The telemetry recordings are shown in Fig. 1B. What is the likely mechanism of the pacemaker spikes seen?
In surface ECG (Fig. 1A), the two QRS complexes without the additional spikes - the third and the sixth - are conducted intrinsic beats. In all other beats, two pacing spikes at fixed intervals are seen, the first one falling at the peak of QRS, and the second at the terminal portion of QRS. The first spike is that of a pseudofusion beat as evident by its timing, and absence of QRS fusion, against the setting of the nearly similar

\footnotetext{
* Corresponding author. Tel.: +91 9995235677.

E-mail address: drdineshchoudhary8@gmail.com (D. Choudhary). 0019-4832/\$ - see front matter Copyright @ 2012, Cardiological Society of India. All rights reserved. http://dx.doi.org/10.1016/j.ihj.2012.08.008
} 
A

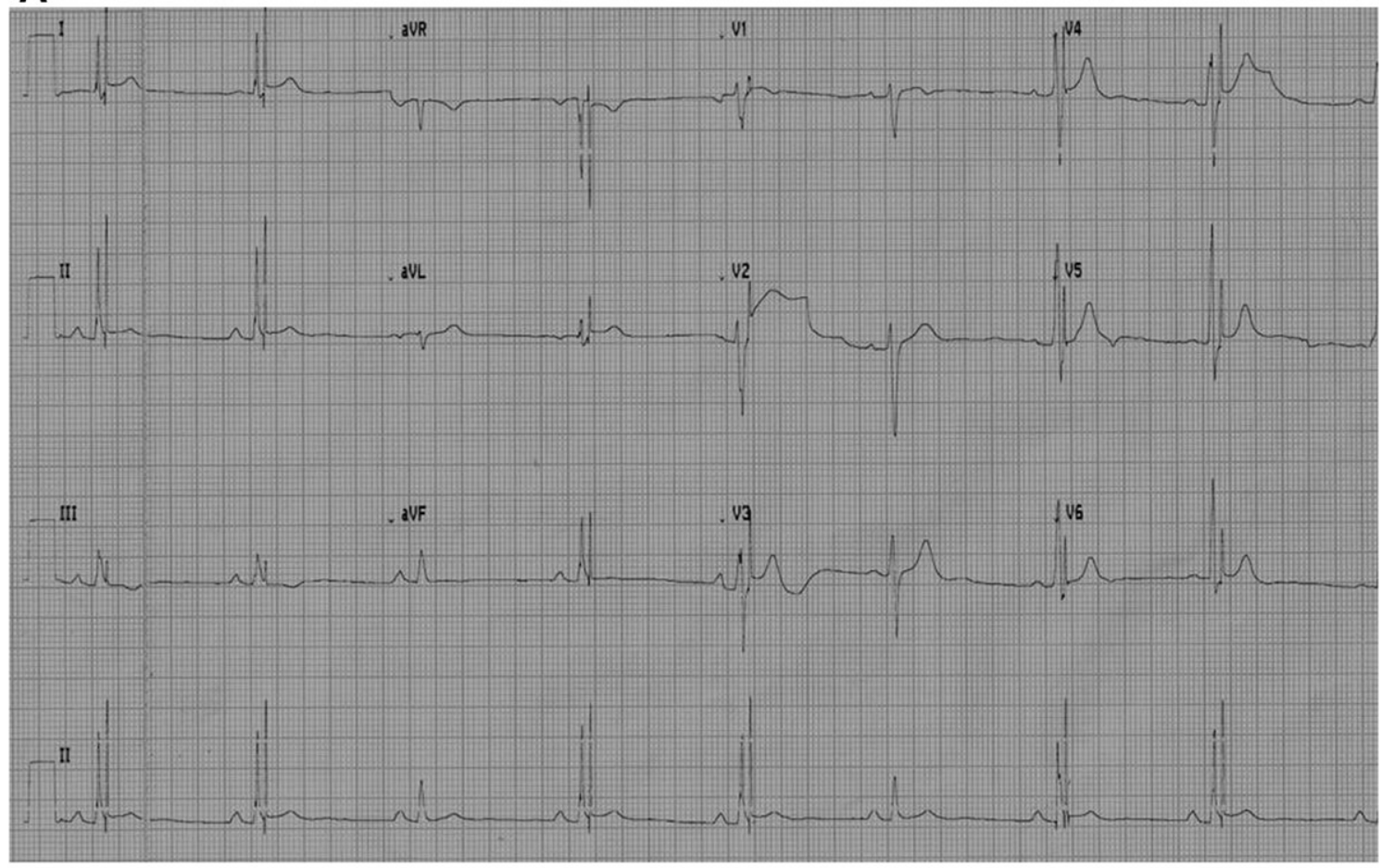

B
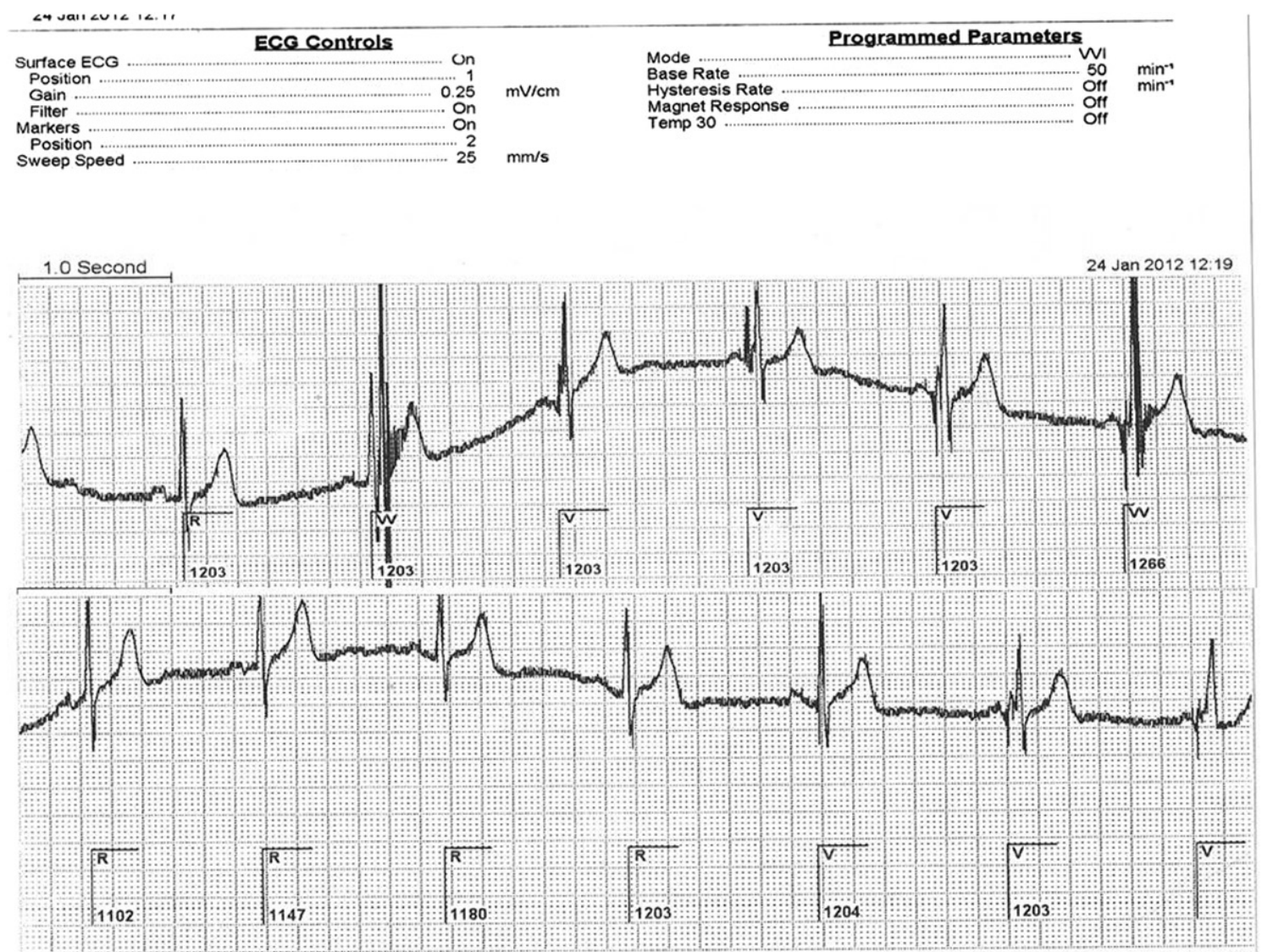

Fig. 1 - (A): Surface ECG showing two pacing spikes except third and sixth beats in rhythm strip. (B): Programming of pacemaker showing two pacing spikes in second and sixth beats simulating sensing failure (mechanism discussed in the text). 
lowest programmed rate $(50 \mathrm{bpm})$ and the intrinsic rhythm. The second beat is a back-up pulse in the AutoCapture (AC) algorithm. This algorithm helps the pacemakers to automatically adjust output close to the pacing threshold. It verifies every single stimulus by monitoring the evoked response signal from myocardial depolarization, and delivers a high output back-up pulse if there is a loss of capture. ${ }^{1-3}$

In the QRS complexes with two spikes, as the first stimulus pseudofusion spike resulting from competing pacemakers did not capture, the pacemaker delivered a high output back-up pulse, which also failed to capture due to physiological refractoriness. As per the AC algorithm by St. Jude Medical, the search interval ( $46 \mathrm{~ms}$ ) for the evoked potential is preceded by a short blanking period (14 ms) which starts with the pacing spike. When the pseudofusion spike (and subsequent search interval) happened well after the onset of QRS (the second and the sixth complexes in upper row, Fig. 1B), the amplitude of local evoked potential was likely to be low to be sensed by the pacemaker, and hence the back-up pulse was delivered. However, the local evoked potential was significant enough to be sensed during the search interval when these spikes occurred relatively early (the last three complexes in lower row, Fig. 1B), and the back-up pulse was withheld. This normal pacemaker behavior, with two pacemaker spikes on the QRS complexes in a patient with VVI pacemaker, simulating a sensing failure, demands the following pre-requisites: similar rate of intrinsic rhythm and lower programmed rate to allow pseudofusion beats, and insufficient local evoked potentials to prompt the pacemaker to deliver the back-up pulse. These 'additional spikes' disappeared on keeping the hysteresis on.

\section{Conflicts of interest}

All authors have none to declare.

\section{R E F E R E N C E S}

1. Clarke M, Liu B, Schüller $\mathrm{H}$, et al. Automatic adjustment of pacemaker stimulation output correlated with continuously monitored capture threshold: a multicenter study. Pacing Clin Electrophysiol. 1998;21:1567-1575.

2. Lau C, Cameron DA, Nishimura SC, et al. A cardiac evoked response algorithm providing threshold tracking: a North American multicenter study. Pacing Clin Electrophysiol. 2000;23:953-959.

3. Ribeiro AC, Rincon LG, Oliveira BG, Vinha CR, Melatto D, Torres AA. Automatic adjustment of pacing output in the clinical setting. Am Heart J. 2004;147:127-131. 